\title{
ENTREVISTA COM HERMANN POHLMANN
}

Gentilmente traduzida do Alemão por Claudia Vivacqua de Figueiredo para a Palíndromo.

Kinceler - Hermann, segundo suas próprias palavras: "a crise que se expande com rapidez crescente no leste e no oeste procura por novas formas de convivência social, e por novas formas de uma administração mais justa. Nesse sentido, Rudolf Steiner preparou "modelos" para uma nova estruturação do organismo social. Um desses modelos é a economia associativa. Em diferentes projetos de uma agricultura apoiada pela comunidade (CSA=community supported agriculture), procuramos converter essa forma de administração em um campo de exercício para uma obra de arte social, uma escultura social." Hermann, desde o pensamento de Joseph Beuys e passados quase quarenta anos, o que hoje podemos entender por escultura social?

HERMANN: Joseph Beuys trabalhou profundamente as questões do futuro. A escultura social é uma tarefa para o futuro, na qual nós na atualidade nos encontramos muito distantes. Só podemos reconhecê-la em breves momentos. Em momentos em que ela emerge e logo em seguida submerge. A escultura social é em primeiro lugar um processo de transformação de todas as conexões humanas para uma verdadeira liberdade, igualdade e fraternidade. Para isto nós precisamos de locais de treinamento, como por exemplo: CSA (community supported agriculture). De projetos que se ocupam de modelos alternativos como por exemplo, a economia associativa. Segundo Beuys, "No desenvolvimento da alternativa, quer dizer do terceiro caminho, partimos do ser humano. Ele é o escultor da escultura social e na sua medida, e no seu querer, deve direcionar o organismo social. No sentimento e no reconhecimento da dignidade humana, valem hoje, para o homem, três conceitos básicos como necessidades primordiais: 1. Ele quer desenvolver livremente suas aptidões e a sua personalidade e poder empregar livremente suas capacidades em junção com as capacidades de seus próximos para um objetivo reconhecido como cheio de sentido. 2. Ele reconhece que todo tipo de privilégio é uma ferida, inaceitável, insuportável da igualdade de direito da democracia. Ele tem a necessidade de ser reconhecido como cidadão, no que diz respeito a todos os direitos e deveres - nos âmbitos econômicos, sociais, políticos e culturais, como 
igual entre iguais - e poder participar, com o Direito Democrático, em todos os níveis de decisões da sociedade. 3. Ele quer presentear com solidariedade e receber solidariedade

Quem analisa este quadro, tem uma compreensão fundamental, clara, da escultura social, na qual o ser humano como artista forma. Quem diz, que deve haver uma mudança, mas passa por cima da 'Revolução dos Conceitos' e só rebate as manifestações externas das ideologias, irá fracassar. Ele se resignará, se contentará em reformar ou entrará na rua sem saída do terrorismo. Três formas da vitória da estratégia do sistema." (Joseph Beuys, Aufruf zur Alternative (convocação para a alternativa). manifesto de Beuys publicado no Frankfurter Rundschau, 23 de dezembro de 1978)

A revolução dos conceitos é nossa tarefa na atualidade, tanto de forma prática como teórica.

Kinceler - Hermann a noção de sustentabilidade social, econômica e meio ambiental já fazia parte das preocupações de Beuys?

HERMANN: Uma parte desta revolução é a sustentabilidade social, econômica e meio ambiental. Só podemos pensar em liberdade, fraternidade e igualdade se incluirmos esses temas. Um processo real de uma escultura social tem que incluir todos os seres humanos, senão as premissas para que ela possa acontecer, como a igualdade, já não existe. Beuys trabalhou esses três aspectos. Ele foi o co-fundador do partido verde na Alemanha. Toda a sua obra se concentra em uma transformação na totalidade: em uma permanente conferência.

Kinceler - Hermann em que momento de seu processo criativo houve esta passagem para formas que pudessem atuar num conceito ampliado da arte (Beuys)? 
HERMANN: Como estudante eu procurei muito por um caminho que se apresentasse como viável. A partir de Duchamp e outros, este caminho viria a passar por uma transformação. Em Beuys eu descobri "algo" que se revelou a mim como um processo construtivo. Para compreender o conceito de arte ampliada, fui estudar arte em sua forma tradicional, mas este caminho não me ajudou totalmente a desenvolver uma imagem clara deste novo conceito.

Só depois que Beuys pessoalmente me indicou a filosofia de Rudolf Steiner, eu consegui encontrar primeiramente uma porta de entrada teórica para a ideia de escultura social. Para Beuys, o ser humano é uma parte intrínseca desta obra de arte. Ele, o ser humano, é ao mesmo tempo o material e com suas ideias o portador desta escultura social e paralelamente ele é plasmado, formado por todos os envolvidos. Todo este processo se dá de forma conjunta aonde um todo se forma (Gestalt).

Os escritos de Rudolf Steiner, sua antropologia, nós dá a base para a compreensão deste processo: formar e ser formado ao mesmo tempo. Sem esta antropologia, não conseguiríamos verdadeiramente trabalhar em conceitos como liberdade, igualdade e fraternidade.

\section{Kinceler - Hermann, como surgiu a proposta Monte Azul em seu caminho?}

HERMANN: Eu precisava vivenciar um exemplo prático e o encontrei no trabalho realizado pela Associação Comunitária Monte Azul. Só a compreensão teórica não me satisfazia mais. Neste local, no Brasil, pude experimentar o que pode significar uma escultura social. O que significa um "organismo caloroso" de que a "revolução dos conceitos" e as permanentes conferências necessitam para se tornarem práticas reais. Até este momento minhas perguntas em relação aos conceitos de liberdade, igualdade e fraternidade a partir de uma "qualidade de calor" (que Beuys descreve como capacidade de amor) haviam sido trabalhadas teoricamente. A escultura social é um "ser do futuro". Na Associação Comunitária Monte Azul ela emerge em alguns momentos. O que impulsiona o trabalho da A.C. Monte Azul é este futuro. É possível descrever a Monte Azul rapidamente (o externo). Os trabalhos realizados e 
atuais são por si só, dignos de admiração. Suas diversas áreas de atuação a tornam um trabalho especial. Mas, o mais importante, mais especial, são as diversas biografias dos moradores, funcionários, voluntários, visitas, estudantes e outros a partir do encontro com a Monte Azul.

Através do contato com escolas e indústrias no exterior e aqui, se tenta uma transformação na comunidade e fora dela. Os muitos diálogos com pessoas de diferentes classes sociais; em países desenvolvidos ou em desenvolvimento - Uma educação que visa a harmonização do ser humano no seu pensar, sentir e querer na qual a diferença entre doador e "recebedor" começa a se diluir.

A pergunta social em uma comunidade não é de cunho abstrato, mas humano. São pessoas que sofrem de forma extrema as consequências materiais, internas e espirituais que resultam do capitalismo e da globalização. O que desejamos é abarcar este problemática a partir de seu aspecto humano e não só do ponto de vista político e econômico. O lado invisível da Monte Azul (seu interior) como organismo vivo são os encontros humanos, seus sentimentos e ações e assim se forma novamente um pensamento conjunto. Assim surge uma comunidade social, com cada uma de suas habilidades e ao mesmo tempo renova as suas forças. Nas conferências pedagógicas, reuniões de comissões, na área da saúde, nos dias de estudos, nas festas, nos aniversários, dias festivos de trabalho, excursões, dançando e cantando se plasma o que é o verdadeiro coração da A. C. Monte Azul. Todos esses aspectos internos e externos são uma tentativa de formar uma comunidade fraterna e sem preconceitos (pré-conceitos). Os funcionários, independente de estudos e classes sociais (padeiro, médico, faxineira, psicóloga e outros), sempre tem o direito a expressar suas opiniões nas reuniões gerais ou diárias. É indiferente se tem formação acadêmica ou, se acabou de aprender a ler ou escrever.

A questão salariais, tratada por uma comissão, procura novas formas de trabalhar este tema, tentando ser justo em relação às remunerações. Tentando não ferir a esfera pessoal dos profissionais. "Trabalho não pode ser vendido, não se pode medir o valor do trabalho em dinheiro." (Renate Keller Ignacio , Co Fundadora da A. C. Monte Azul). Um organismo social é muito mais que a soma de seus funcionários. 
É quando cada um se esforça para disponibilizar suas habilidades para a comunidade. Esse esforço individual se transforma em educação e auto-educação. "O aprendizado se amplia e não paramos de aprender." (Üte Crämer. Favela M. Azul, pg. 67) Aqui o ser humano plasma como artista "a obra de arte mais completa. A construção de uma verdadeira liberdade política. (Frederich Schiller ,A Educação Estética do Homem, 1975) É um trabalho artístico constante de criar a forma adequada ao conteúdo, procurando equilíbrio entre o formalismo (burocracia) e o caos. Instalar este equilíbrio é um ponto central no processo da escultura social. Apesar de na Monte Azul as pessoas não se denominarem como parte de uma escultura social (como artistas em seus locais de trabalho), elas se sentem trabalhando em prol de uma obra de arte.

\section{Kinceler - O que foi proposto para a Bienal de São Paulo?}

A proposta era apresentar cada um em seu local de trabalho, como um artista. Um escultor da escultura social da forma como Beuys pensou. Seria um exemplo prático. A A. C. Monte Azul como exemplo de escultura social em São Paulo. Apresentar de forma viva a revolução dos conceitos e a conferência permanente. Os visitante da Bienal seriam transladados de ônibus até a comunidade, para conhecêla e participar das atividades e seminários organizados para este fim. No prédio da Bienal, uma central que divulgaria e organizaria o proposto.

\section{Kinceler - Hermann pode nos falar um pouco do histórico do movimento do CSA?}

HERMANN: O conceito de uma agricultura sustentada em conjunto foi incentivada nos anos 60 pelo movimento da trimembração social, apoiada e concretizada pelos fundadores do Banco GLS, Wilhelm Ernst Barkoff e Albert Fink, em Fuhlhagen, perto de Hamburgo, na fazenda Buschberg, com 350 consumidores e a participação de 3 fazendas. Hoje ela serve de modelo para inúmeros projetos no mundo. Nos EUA estabeleceu-se um amplo movimento denominado CSA, Community Supported Agriculture (agricultura apoiada pela comunidade), que provê cerca de um 4 milhão 
de participantes. No Japão, há cerca de 20 milhões de participantes, um quarto da população japonesa, sob o nome de Teikei. (http://www.joaa.net/english/teikei.htm)

\section{Kinceler - Hermann como estão os projetos dos CSA em Demetria, Campinas e CSA Maria da Fé}

HERMANN: Nossos agricultores da CSA Demétria em Botucatu, assim como em Campinas e Maria da Fé, conseguem alimentar, cada uma, aproximadamente 500 pessoas (200 famílias) com legumes, pão, leite e laticínios, e ovos (também carne, em certa medida). Essas 500 pessoas financiam a agricultura com contribuições mensais, de modo que os agricultores podem concentrar-se totalmente em seu verdadeiro trabalho, o cultivo orgânico.

O círculo de consumidores compromete-se a sustentar as despesas da fazenda pelo período de um ano. É um sistema com vantagens para dois lados: os agricultores não mais precisam atingir um certo resultado de vendas, e podem estruturar a produção agrícola em liberdade, sem pressão de preços e do mercado; os consumidores obtêm os alimentos produzidos pelo empreendimento durante um ano, sem custos adicionais. Dessa maneira a responsabilidade pela agricultura é carregada conjuntamente por todos. Em poucas palavras, CSA significa uma agricultura sustentada por todos. Baseados nessa nova forma de produção agrícola, os agricultores podem colocar à disposição uma gama bastante variada de oferta de produtos. Legumes, verduras, temperos, ovos, frangos, queijos, pão preparado por eles mesmos e carne - tudo da melhor qualidade orgânica e biodinâmica. Atualmente, associando-se à comunidade agrícola em três projetos de CSA, pessoas de Botucatu, Bauru, Campinas, Atibaia, Itajubá, Maria da Fé, Itatiba e São Paulo decidiram assumir em conjunto a responsabilidade para com a agricultura biodinâmica e orgânica de uma fazenda ou sítio, e assim, assumir a responsabilidade para com uma agricultura em consonância com a natureza, a proteção ativa da natureza e o cuidado da paisagem. As vantagens de uma CSA, apenas para citar algumas, são maior regionalidade, menores distâncias para 0 transporte, convivência pessoal, criação e manutenção de postos de trabalho na agricultura. A CSA foi um dos conceitos favoritos no Fórum Social Mundial de 2001 
em Porto Alegre. Ela baseia-se na ideia da trimembração de Rudolf Steiner e, entrementes, está muito difundida nos EUA e na Europa. Para os membros de uma CSA há, semanalmente, uma rica colheita. Os produtos podem ser buscados uma vez por semana em diversos depósitos na proximidade dos consumidores. A quantidade dos produtos é dividida pelos membros entre si. Não há caixas previamente preparadas.

\section{Kinceler - Quais os objetivos de uma CSA?}

HERMANN: Em princípio, nosso objetivo é encontrar os consumidores na região dos produtores, a fim de evitar transporte para locais distantes. Atualmente vários agricultores viajam duas vezes por semana para a cidade de São Paulo, a fim de vender seus produtos em feiras. Um inacreditável gasto de tempo e energia, que faz falta no campo, um enorme desgaste familiar para os agricultores e ao mesmo tempo uma grande carga para o meio ambiente. Em paralelo, estamos preparando pequenos agricultores na periferia de São Paulo para outros projetos de CSA, para aliviar os produtores de regiões distantes. Por força da lei, todos os pequenos agricultores nas proximidades de São Paulo devem passar para uma produção ecológica, de modo a não mais por em risco a água potável da cidade. O problema dos pequenos agricultores é a comercialização de produtos produzidos ecologicamente. Hoje eles são forçados a oferecer seus produtos no mercado convencional pelo mesmo preço de antes, embora tenham mais trabalho; portanto, eles não apoiam intimamente a produção ecológica, e a maioria até mesmo a rejeita. A ideia de uma comercialização do tipo CSA vem bastante ao seu encontro. e isso pode dar origem a novos projetos.

Como meta espiritual, o objetivo de uma CSA é despertar nos consumidores, por meio de uma tal comunidade de produtores e consumidores, uma compreensão da agricultura como um organismo agrícola, e levar os produtores a uma diversidade de cultivos, como um organismo agrícola em conjunto com planta e animal, ser humano e terra; como meta social, possibilitar que todos os participantes tenham acesso a um solo fértil; e como meta econômica, produzir uma variedade de produtos. Esses objetivos protegem as pessoas e o meio ambiente. 
A ligação direta com os clientes é de grande interesse para a agricultura, especialmente para os empreendimentos familiares. Essa ligação clara e bem definida assegura o sustento do agricultor e postos de trabalho, e the permite fazer um planejamento eficaz a longo prazo. Ele pode concentrar-se em sua tarefa e não precisa preocupar-se com a comercialização. Divide todos os riscos com 0 consumidor. Este, por meio de sua participação, transforma-se em um "agricultor passivo". Estabelecem-se não apenas acordos econômicos, mas também amizades e trabalho em conjunto. Devido ao planejamento dirigido, venda direta e menos resíduos de embalagens, o agricultor passivo também obtém alimentos com preço acessível, saudáveis e frescos. Assim, o meio ambiente é o maior beneficiário do projeto. Por causa do transporte de curta distância, ausência de excesso de produção, com planejamento dirigido da quantidade cultivada, e por meio da ajuda e controle da comunidade, o agricultor pode dedicar-se totalmente a um cultivo ecológico.

\section{Kinceler - Quais os aspectos inovadores de uma CSA?}

HERMANN: O aspecto inovador desse projeto é o apoio conjunto e assumir conjuntamente a responsabilidade pela produção de nossos alimentos e pelo nosso consumo, e a criação de confiança em ambos os lados. O consumidor deve confiar em receber alimentos saudáveis e em quantidade suficiente, e que o agricultor cumpre a reivindicação de um cultivo ecológico. O agricultor deve confiar que o consumidor lhe dê o apoio tanto financeiro quanto aos seus ideais, e cumpra seus compromissos de longo prazo. Segundo a experiência de outros projetos de CSA, aqui a força está na comunidade que, devido ao seu engajamento, solicita um nível jurídico justo (quanto custa, o que eu recebo), assim como cuida de um nivelamento social por meio de contribuições sociais, ao sustentar financeiramente famílias menos favorecidas. Examinando-se todas essas relações, surge uma vida espiritual na fazenda e em torno dela. Porém, não somente os lucros são divididos, mas também todos os riscos. Assim, perdas de colheitas são suportadas em conjunto. Projetos de CSA não se baseiam em crescimento quantitativo, mas sim em crescimento qualitativo. Quem já participou de um projeto de CSA, conhece a riqueza em proximidade pessoal, crescimento e transformação do projeto. Este 
desenvolve-se em um organismo vivo, um campo de exercício da trimembração e arte sociais. Do ponto de vista quantitativo, é importante que nos lares haja variedade de alimentos. Do ponto de vista qualitativo, os alimentos transformam-se tanto na produção como na mão do consumidor, que desenvolve uma relação totalmente diferente para com os produtos. A fazenda torna-se "a minha fazenda". O consumidor começa a ser parte do organismo, e o produtor aprende a compreender seus agricultores passivos como ser humano. 6 Dificuldades podem ocorrer quando se erra no cálculo, quando as questões financeiras não são apresentadas de maneira transparente, o contato entre os agricultores e os consumidores não é bem cultivado, ocorrem grandes perdas na colheita ou a fase de transição se alonga demais. Por causa da comercialização tradicional e a estruturação paralela da comunidade, o agricultor tem de suportar uma carga dobrada na fase de transição.

\section{Kinceler - Pelo que estou entendendo a meta não é fazer crescer apenas alimento, mas principalmente promover consciência?}

HERMANN: A CSA não pretende ser um conceito pronto, mas a consideração básica que todos os seres humanos deveriam ter novamente uma relação maior com a agricultura, e assim reconhecer sua importância. Na medida em que, por um ano, eles assumem a responsabilidade- especialmente do ponto de vista financeiro - para com um empreendimento agrícola específico em sua região, eles devem desenvolver uma compreensão para com os seus problemas, mas também experimentar o valor cultural de uma agricultura ecológica diversificada.

Não temos todas as respostas, mas podemos formular algumas perguntas. Como podemos realizar a agricultura de maneira eficaz? Como podemos proteger não só a terra, mas também o agricultor? A agricultura industrializada não é a resposta.

A CSA apresenta uma possibilidade de transformar em prática as considerações em nível social, ecológico, econômico, espiritual, legal, cultural e pedagógico. Tenta-se possibilitar a participação de pessoas com poucos recursos financeiros por meio de acordos distintos (cada um paga o quanto pode, e as quantias faltantes podem ser compensadas mediante colaboração). Atividades coletivas (festas na fazenda etc.) 
são realizadas para reforçar o contato dentro da comunidade. Às vezes também se trocam habilidades individuais - p.ex., um advogado pode dar aconselhamento legal. Nas fazendas, excursões, jornadas e eventualmente ensino teórico ao lado do trabalho, devem permitir um acesso claro a temas agrícolas para crianças e adultos. Apesar das características aqui enumeradas, frequentemente encontradas em uma CSA, é importante que cada fazenda desenvolva seu próprio conceito individual, dependendo da composição de seus membros e dirigentes, da localização e do tamanho. Se existe uma compreensão comum entre as pessoas que têm a ver com fazendas comunitárias, ela tende a ser a seguinte: "Não existe um modelo que possa ser aplicado universalmente. Cada novo grupo que está iniciando deve avaliar seus próprios objetivos, capacidades e meios, e tomá-los como ponto de partida."( http://www.buschberghof.de/Seiten/CSATheorie.html )

"Pois não é dito: isto deve ser organizado desta ou daquela maneira. Aponta-se apenas para como as próprias pessoas, se quiserem viver em comunidade, vão organizar as coisas de modo que estas correspondam à sua compreensão e seus interesses." ( Steiner, R. Die Kernpunkte der Sozialen Frage. GA 23, S. [p.] 15. Os Pontos Centrais da Questão Social. São Paulo: Ed. Antroposófica, 2011.)

\section{Kinceler - Como acontece o processo de mediação artística numa CSA?}

HERMANN: O trabalho é sustentado primordialmente por um número sem fim de conversas pessoais, visitas aos domicílios e ao trabalho, de engajamentos em tarefas, reuniões, observações, meditações, comer e cozinhar em conjunto, cantar e dançar. Temos pelo menos um encontro mensal com os agricultores "ativos" e os "passivos"; na Demétria, eles são até mesmo semanais. Além de todas as questões práticas, neles também se conversa sobre perguntas sobre arte. Um fenômeno que se manifesta é que no dia da entrega dos produtos percebe-se uma atmosfera muito emotiva, que preenche a alma. Ela não vale para muitos. De início ela também pode não estar de acordo com uma concepção tradicional de arte, mas sente-se que essa atmosfera é comparável com o estado de alma que se tem quando se observa uma obra de arte ou se ouve um concerto. Ao lado de todos os argumentos convincentes desse projeto, essa atmosfera é certamente a vivência mas linda. 


\section{Kinceler - Como a educação estética participa neste processo?}

HERMANN: No entanto, sem educação estética tudo isso cai no vazio. Como seres humanos temos que nos preparar em paralelo. Por meio da arte nós nos formulamos. Para o ser humano a arte é um caminho de desenvolvimento. Levar para um estado de suspensão lúdico os opostos incompatíveis, de modo sério e ao mesmo tempo sem seriedade. Metaforicamente, a qualidade que se pode aplicar na direção, isto é, aliviar a seriedade, relaxar, não se deixar dominar por ela. Nesse sentido, recomenda-se autoeducação.

"Pois, para expressá-lo finalmente de uma vez, o ser humano só brinca quando for humano no sentido pleno da palavra, e ele só é totalmente ser humano quando ele brinca. [...] Se estiver eternamente preso a uma única fração do todo, o ser humano forma-se como uma fração da totalidade; se ouve eternamente no ouvido somente o ruído monótono da roda que ele impulsiona, ele jamais vai desenvolver a harmonia de seu ser e, em lugar de imprimir a humanidade em sua natureza, ele torna-se simplesmente uma cópia de seu empreendimento, de sua ciência."(Schiller, F. Über die ästhetische Erziehung des Menschen [Sobre a educação estética do ser humano], 1795, München: Hanser Verlag, 1984.)

A arte deve permear a vida, caso contrário esta permanece deserta e vazia.

"É importante que o caminho indicado seja trilhado continuamente, em um exercício permanente, incluindo-se os princípios de trabalho mencionados, com uma intensidade que não esmoreça, ao contrário, que cresça, sem se permitir perder a coragem frente a qualquer dificuldade. Continuar levando a chama significa de início que se deve protegê-la e cultivá-la amorosamente junto a si."(Rappmann, R. Arbeitsaspekte des Sozialen Künstlers, Liebevolle Hartnäckigkeit [Aspectos do trabalho do artista social, teimosia amorosa]. Wangen: FIU Verlag, 1986)

Pois "[...] com o amor logo será possível fazer algo no próprio país com o conceito expandido de arte, com a escultura social."(Beuys, J. Sprechen über Deutschland [Conversas sobre a Alemanha] S. 21 [p. 21]. Wangen: FIU Verlag, 2002) 